\title{
The Relationship Between Internet Addiction and Aggression: Multiple Mediating Effects of Life Events and Social Support ${ }^{*}$
}

\author{
Gao Fengqiang, Xu Jie, Ren Yueqiang, Han Lei \\ Shandong Normal University, Ji’nan, P.R. China
}

\begin{abstract}
Objective: To investigate the relationship among Internet addiction, life events, social support and aggression, and figure out the inner deep structure of the four variables. Method: 363 undergraduates were selected via cluster sampling method. They were asked to fill out four questionnaires, including Chinese Internet Addiction Scales revision (CIAS-R), Adolescent Self-Rating Life Events Check List (ASLEC), Perceived social support scale (PSSS) and Aggression questionnaire (AQ). Results: (1) Aggression was positively correlated with Internet addiction and life events, negatively correlated with social support. Internet addiction was positively correlated with life events, negatively correlated with social support; (2) Internet addiction can positively predict aggression; (3) Life events and social support played multiple mediating roles between Internet addiction and aggression. Conclusion: On the one hand Internet addiction directly affects undergraduates' aggression; on the other hand, Internet addiction affects undergraduates' aggression through the multiple mediating effects of life events and social support.
\end{abstract}

Keywords: Internet addiction, aggression, life events, social support

\section{Introduction}

Aggression is a kind of common negative behavior, which has three basic characteristics: damage intentions, damage behavior and damage consequences (Luo, 2008). Previous studies found that aggression behavior could be influenced by many factors, such as personal factors including personality (Luo, 2008; Denson, DeWall, \& Finkel, 2012), interpersonal barriers (Ji, Wei, Chen, \& Zhang, 2012), biological factors (Wang \& Zhang, 2010), etc., family factors including parental rearing styles (Luo, 2008; Lv, Chen, \& Wang, 2003), family environment (Lv et al., 2003; Barrett, Rapee, Dadds, \& Ryan, 1996; Sijtsema, Oldehinkel, Veenstra, Verhulst, \& Ormel, 2014), etc., and social factors including frustration and pressure (Taylor, \& Kluemper, 2012; Riley, Watt, Richardson, \& De Alwis, 2012), media violence (Fisoun, Floros, Geroukalis, Ioannidi, Farkonas, \& Sergentani, 2012; Mehroof \& Griffiths, 2010; Polman, De Castro, \& Van Aken, 2007), etc. With the rapid development of information technology and the popularity of the Internet, "Internet

\footnotetext{
*Acknowledgments: This work was supported by National Social Science Foundation of China (13BSH061), Humanities and Social Sciences Foundation of Ministry of education of China (12YJC190009), Shandong Provincial Natural Science Foundation, China (ZR2015CQ010), Science and Technology Development Project of Shandong Province, China (2013GSF11802), Key Laboratory of Adolescent Cyberpsychology and Behavior (Central China Normal University ) (Open subject NO.2012C13) and The Key Discipline Construction Program of 12th Five-Year Plan of Shandong Province (Developmental and Educational Psychology).

Gao Fengqiang, Ph.D., School of Psychology, Shandong Normal University.

Xu Jie, M.Ed., School of Psychology, Shandong Normal University.

Ren Yueqiang, M.Ed., School of Psychology, Shandong Normal University.

Han Lei, Ph.D., School of Psychology, Shandong Normal University.
} 
addiction" of the college students is becoming more and more serious. It affects various aspects of college students' study and life (Wang \& Li, 2012). And then the relationship between Internet addiction and aggression has caused wide attention of scholars both at home and abroad. Mehroof and Md. (2010), Polman et al. (2007) and others' studies showed that Internet addiction was significantly correlated with aggression.

According to the General Aggression Model built by Anderson and Bushman (2002), personal factors (traits, attitudes, genetic susceptibility etc.) and situational factors (violent videos or games, provocation, frustration etc.) affect individual aggression through the internal state including emotion, awakening, cognition etc. Researches indicated that Internet addicts surfed on the Internet for online games, chat, multimedia entertainments, browsing the news or information, etc. While online videos and games mostly contain violent images, so Internet addicts are always exposed to violent situations. Then the suggestive clues existing in violent situations could lead to aggression (Kang, Yang, \& Wang, 2006). Young (1998) put forward eight major characteristics of Internet addiction. One of the characteristics was environmental pressures, including pressures from family, school, work, friends, etc. As a consequence, Internet addicts will encounter more negative life events (Akin \& Iskender, 2011; Jun \& Choi, 2015) and experience less social support (Csibi \& Csibi, 2011; Wang \& Wang, 2013; Gunuc \& Dogan, 2013). Life events refers to the spirit of hard hit and adversity in the daily work, life or learning. College students' life events contains broader extension, such as being criticized, being bullied, academic pressure, interpersonal pressure, health problems and so on. Studies have shown that life events are related to individuals' psychology, behavior and body problems (Rabkin \& Struening, 1976). Social support refers to beneficial interpersonal communication which protecting people from the negative effects of stressful events (Cohen \& Wills, 1985). It is one of the important factors influencing people to adapt to the social environment, and is also one of the important resources as a kind of cognitive evaluation. The unfavorable situational factors (long-term exposure to violent situations, encountering more negative life events and experiencing less social support) facing by Internet addicts will probably be easier to lead to aggression.

As is known to all, we are living in an era of network. Our life has been inseparable from the network, even if we know the network may lead to Internet addiction and other negative effects, we still need to rely on the Internet to survive. Various results showed that there were a certain number of college students addicted to the Internet and such phenomenon could almost affect their normal life. For example, $80 \%$ of the 237 dropouts in a university of domestic were addicted to the Internet and could not get a normal score, so that they could not complete their studies and then were forced to drop out of school. In the same way, 13 students of 205 dropouts in a university of a province could not pass the exam were also associated with unrestrained access to the Internet (Bai \& Fan, 2005). However, the negative impact of Internet addiction is not only reflected in the harm of their own, but also in the harm of social and others. One of the most common harm is aggression, it has already been discussed in the preceding part of the text. There have been many relatively mature theory of aggression, such as Script Theory offered by Huesmann (1986), Excitation Transfer Theory offered by Zillmann (1983), Social Interaction Theory offered by Tedeschi and Felson (1994). These theories were put forward to help us understand the reasons of aggression better, and to prevent and solve the problems of aggression from the reasons. As already mentioned, Internet addicts would encounter more negative life events (Akin \& Iskender, 2011; Jun \& Choi, 2015) and experienced less social support (Csibi \& Csibi, 2011; Wang \& Wang, 2013; Gunuc \& Dogan, 2013) and then lead to aggression easier. So what should we do regarding to the phenomenon we encountered? How to solve the status we are faced with? 
To investigate the relationship among Internet addiction, life events, social support and aggression, we took Internet addiction as independent variable and aggression as dependent variable to establish Structural Equation Model (SEM). So that we could investigate the multiple mediating roles of life events and social support between Internet addiction and aggression in order to figure out the inner deep structure of the four variables. We can further understanding the reasons and mechanism why Internet addiction lead to more aggression.

\section{Method}

\section{Participants}

The participants were selected from a university in Shandong Province, China by random cluster sampling. The original sample was 350 students. After removing invalid questionnaires, the remaining valid subjects were 335, consisted of 166 boys and 169 girls, aged from 17 to 24 years ( $M=19.90$ year, $S D=1.69$ years).

\section{Measures}

Chinese Internet Addiction Scale-R (CIAS-R). CIAS-R was revised by Bai and Fan (2005). The scale has 19 items containing four dimensions: Withdrawal Symptoms of Internet Addiction (Sym-W), Tolerance Symptoms of Internet Addiction (Sym-T), Interpersonal and Health-Related Problems of Internet Addiction (RP-IH) and Time Management Problems (RP-TM). It used 4-point scale. The total scores represented the degree of individual's Internet addiction, less than 46 were divided into normal, greater than 53 were into the Internet addiction, 46-53 were into Internet dependence. In this study, Cronbach's alphas for this scale were 0.93.

Adolescents Self-Rating Life Events Checklist (ASLEC). ASLEC was complied by Liu (1997). It was suitable for teenagers, especially for middle school students and college students for evaluating the incidence and stress intensity life events. The scale has 27 items containing six dimensions: Interpersonal Relationship, Learning Stress, Being Punished, Loss, Health Adaptation and Other Stressful Events. The cumulative score was the total amount (Wang, Wang, \& Ma, 1999). It used 5-point scale. The higher scores meant more pressure of negative life events. In this study, Cronbach's alphas for this scale were 0.90 .

Social Support Rating Scale (SSRS). SSRS was complied by Jiang and revised by Wang et al. (1999). The scale has 12 items containing three dimensions: Family Support, Friend Support and Support of Others. It used 7-point scale. The higher scores meant the more grasp of the social support. In this study, Cronbach's alphas for this scale were 0.90 .

Aggression Questionnaire (AQ). AQ was complied by Buss and Warren (2000) and translated by Li (2008). The scale has 34 items containing five dimensions: Physical Aggression, Verbal Aggression, Anger, Hostility and Indirect Aggression. It used 5-point scale. The higher scores meant more aggressive. In this study, Cronbach's alphas for this scale were 0.85 .

\section{Common Method Biases}

Analyze the four questionnaires with common variance analysis by factor analysis. The results showed that $\mathrm{KMO}=0.818$ and it was very suitable for factor analysis. The chi-square of Bartlett's Test of Sphericity reached significant level. After the principal component analysis we extracted 24 eigenvalues greater than 1, and the first factor to explain the variance was only $13.473 \%$, less than $40 \%$ of the critical standard (Podsakoff, MacKenzie, Lee, \& Podsakoff, 2003). We could get the conclusion by the factor analysis that this study did not exist obvious problems of common method biases. 


\section{Data Analysis}

Data analysis of statistics was conducted by SPSS 17.0, using correlation analysis and regression analysis. Data was also analyzed with the help of the Amos 17.0 software package, using the Structural Equation Model (SEM).

\section{Results}

\section{Descriptive Statistics}

Means, standard deviations and the correlation matrix of the variables were presented in Table 1 . The results showed that Internet addiction was positively correlated with life events $(p<0.001)$ and was negatively correlated with social support $(p<0.01)$, aggression was positively correlated with Internet addiction and life events $(p<0.001)$ and was negatively correlated with social support $(p<0.01)$.

Table 1

Descriptive Statistics and Related Analysis Results of the Variables $(N=335)$

\begin{tabular}{lllllll}
\hline Latent variable & $\mathrm{x}$ & $s$ & 1 & 2 & 3 & 4 \\
\hline 1. Internet addiction & 34.07 & 9.99 & 1 & & & \\
2. Life events & 44.35 & 13.36 & $0.24^{* * *}$ & 1 & & \\
3. Social support & 68.74 & 10.96 & $-0.14^{* *}$ & $-0.21^{* * *}$ & 1 & 1 \\
4. Aggression & 74.10 & 14.93 & $0.21^{* * *}$ & $0.25^{* * *}$ & $-0.17^{* *}$ & 1 \\
\hline
\end{tabular}

Notes. ${ }^{*} p<0.05,{ }^{* *} p<0.01,{ }^{* * *} p<0.001$, similarly hereinafter.

\section{Multiple Mediating Model Construction of Life Events and Social Support Between Internet Addiction and Aggression}

There were significant correlations among the variables in Table 1. To further investigate the relationship between Internet addiction, life events, social support and aggression, we took life events and social support as mediating variable, Internet addiction as independent variable and aggression as dependent variable to establish SEM and examining the degree of fitting model.

First we took Internet addiction as independent variable and aggression as dependent variable to establish regression model. The results showed that the path coefficient of Internet addiction to aggression was significantly, $\beta=0.28(t=4.40, p<0.001)$. It meant that Internet addiction had significantly predicted effects to aggression. The fitting index of the regression model was presented in Table 2.

Table 2

The Fitting Index of the Regression Model

\begin{tabular}{lrccccccc}
\hline Index & $X^{2}$ & $d f$ & $X^{2} / d f$ & GFI & NFI & IFI & CFI & RMSEA \\
\hline The Regression Model & 68.11 & 26 & 2.62 & 0.96 & 0.95 & 0.97 & 0.97 & 0.070 \\
The Mediation Model & 279.08 & 130 & 2.15 & 0.92 & 0.90 & 0.95 & 0.95 & 0.059 \\
\hline
\end{tabular}

And then we took life events and social support as mediating variable, Internet addiction as independent variable and aggression as dependent variable to establish SEM. The results were presented in Figure 1. Internet addiction had positively predicted effects to life events, the path coefficient $\beta=0.25(t=4.06$, $p<0.001)$; life events had positively predicted effects to aggression, the path coefficient $\beta=0.25(t=3.76$, $p<0.001$ ); Internet addiction had negative predicted effects to social support, the path coefficient $\beta=-0.17$ 
( $t=-2.78, p<0.01$ ); social support had negative predicted effects to aggression, the path coefficient $\beta=-0.14$ $(t=-2.29, p<0.05)$. The direct effect of Internet addiction to aggression was $0.20(t=3.06, p<0.01)$, the indirect affect of Internet addiction to aggression through life events and social support as mediating variable was 0.087 . Based on the Bootstrap test, if the path coefficient of $95 \%$ confidence interval did not include 0 , the indirect effect is significant. In this study, the path coefficient of $95 \%$ confidence interval of the indirect effect of Internet addiction to aggression was [0.042, 0.151], so the indirect effect was significant. Thus it could be seen the direct and indirect effect of Internet addiction to aggression were significant after joining the two mediating variable of life events and social support. It conformed to the judgment standard of partial mediation effect. The mediating effect of life events and social support between Internet addiction and aggression was significant, and the mediation rate was $30.53 \%$. The fitting index of the mediation model was presented in Table 2 .

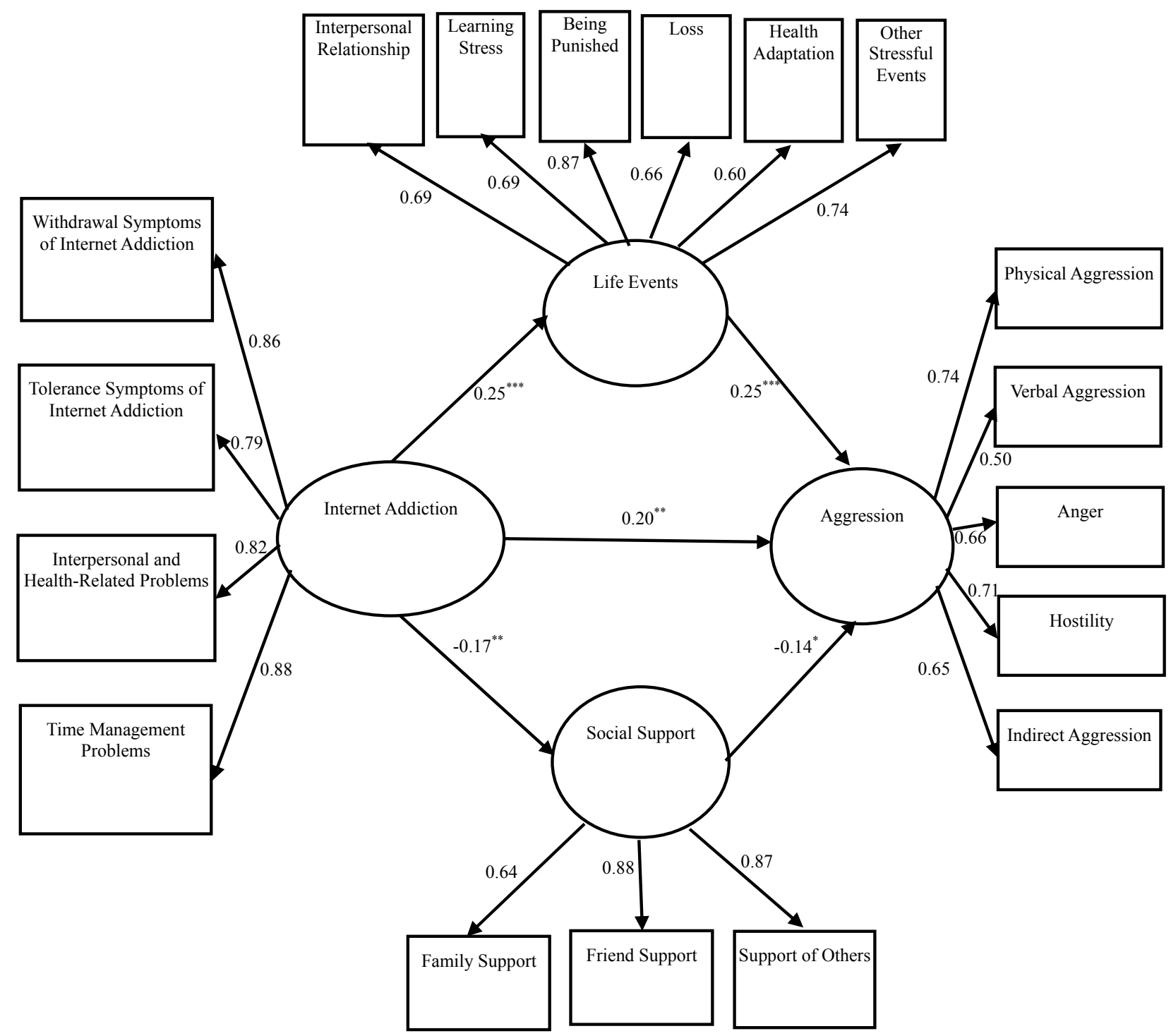

Figure 1. Multiple mediating effects of life events and social support between internet addiction. 


\section{Discussion}

Seen from the results of correlation analysis, the variables investigated in this study (Internet addiction, life events, social support, aggression) had significant correlation. The higher scores of individual's Internet addiction, the higher level of aggression. Internet addiction did have direct influence on aggression, the results were consistent with previous research results (Fisoun et al., 2012; Mehroof \& Md., 2010; Polman et al., 2007). There are lots of violent content in the Internet. According to the Social Learning Theory, individuals can get violence behaviors unconsciously and reduce the inhibition of violence in the Internet violence for a long time so that the aggression will be strengthened. The higher scores of negative life events meant the higher level of aggression. Negative life events can cause frustration for individuals. According to the Theory of Frustration-Aggression, frustration is the prerequisite of aggression and there are unconditional causality between them. The lower scores of social support meant the higher level of aggression. The results were also consistent with previous research results (Csibi \& Csibi, 2011; Sun, Guan, Tan, Zhang, \& Fan, 2013). Social support is considered as one of the protection factors of aggression (Benhorin \& McMahon, 2008). Individuals who were addicted to the network and spend a lot of time and energy on the Internet, got less social support. At the same time, they would experience more negative life events and pressure from family, study, work and communication.

Seen from the results of SEM, the direct effect of Internet addiction to aggression was still significant after joining the two mediating variable of life events and social support. We could see that on the one hand Internet addiction directly affected college students' aggression, on the other hand Internet addiction affected college students' aggression through the two mediating variable of life events and social support. It can lead to enhance individuals' aggression when they are directly exposed to the environment of Internet violence. And furthermore Internet addiction enhanced individuals' aggression by increasing their negative life events and reducing their social support. Therefore, the current study verified the influence of different variables and the mechanism in the General Aggression Model (violent videos or games, frustration, social support, etc.). We can further understanding the reasons and mechanism why Internet addiction lead to more aggression.

In general, on the one hand, the current research were consistent with previous research results and fully verified the previous conclusions. This also proved the authenticity and credibility of our study from the side. We not only found out the the relationship between Internet addiction, life events, social support and aggression, and also found out the mechanism why Internet addiction lead to more aggression. It had important theoretical significance for our psychological research. On the other hand, theory always serves for practice. Now that we got some theoretical results from this study, we should apply the results fully in practice. First of all, we should properly guide students to surf on the Internet and try to avoid Internet addiction. Second, we should let students to contact with the positive energy in the society, and help the students build correct and healthy outlook on life, world outlook and values. Then, we should give college students more support, whether family, school, friends or others all should believe and support the college students' life ideals.

\section{Conclusion}

The present study demonstrates the relationship between Internet addiction, life events, social support and aggression. It showed the following conclusions: (1) Internet addiction can positively predict aggression. (2) Life events and social support partly mediated the relationships between Internet addiction and aggression. 


\section{References}

Akin, A., \& Iskender, M. (2011). Internet addiction and depression, anxiety and stress. International Online Journal of Educational Sciences, 3(1), 138-148.

Anderson, C. A., \& Bushman, B. J. (2002). The effects of media violence on society. Science, 295(5564), 2377-2379.

Bai, Y., \& Fan, F. (2005). A Study on the Internet dependence of college students: The revising and applying of a measurement. Psychological Development and Education, 21(4), 99-104.

Barrett, P. M., Rapee, R. M., Dadds, M. M., \& Ryan, S. M. (1996). Family enhancement of cognitive style in anxious and aggressive children. Journal of Abnormal Child Psychology, 24(2), 187-203.

Benhorin, S., \& McMahon, S. D. (2008). Exposure to violence and aggression: Protective roles of social support among urban african american youth. Journal of Community Psychology, 36(6), 723-743.

Bryant, J., \& Zillmann, D. (1983). Sports violence and the media sports violence. Springer New York.

Cohen, S., \& Wills, T. A. (1985). Stress, social support, and the buffering hypothesis. Psychological Bulletin, $98(2), 310$.

Csibi, S., \& Csibi, M. (2011). Study of aggression related to coping, self-appreciation and social support among adolescents.. Nordic Psychology, 63(4), 35-55.

Denson, T. F., DeWall, C. N., \& Finkel, E. J. (2012). Self-control and aggression. Current Directions in Psychological Science, 21(1), 20-25.

Fisoun, V., Floros, G., Geroukalis, D., Ioannidi, N., Farkonas, N., \& Sergentani, E., et al. (2012). Internet addiction in the island of hippocrates: The associations between Internet abuse and adolescent off-line behaviours. Child \& Adolescent Mental Health, 17(1), 37-44(8).

Gunuc, S., \& Dogan, A. (2013). The relationships between Turkish adolescents' Internet addiction, their perceived social support and family activities. Computers in Human Behavior, 29(6), 2197-2207.

Huesmann, L. R., \& Malamuth, N. M. (1986). Media violence and antisocial behavior: an overview. Journal of Social Issues, $42(42), 1-6$.

Ji, L., Wei, X., Chen, L., \& Zhang, W. (2012). Peer relationship adversities and children's aggression during late childhood: The mediating roles of self-conception and peer beliefs. Acta Psychologica Sinica, 44(11), 1479-1489.

Jun, S., \& Choi, E. (2015). Academic stress and Internet addiction from general strain theory framework. Computers in Human Behavior, 49, 282-287.

Kang, T., Yang, W., \& Wang, P. (2006). The effects of hint clues and goal information on the college students' judgment of aggression possibility. Psychological Exploration, 26(3), 69-73.

Li, L. (2008). A study on reliability and validity of aggression questionnaire and city norm of Hubei Province (Doctoral dissertation, HuaZhong Normal University, 2013).

Luo, G. (2008). Researches on the relationships among parental rearing style, self- esteem and aggression in college students. Chinese Journal of Clinical Psychology, 16(2), 198-199.

Lv, Q., Chen, H., \& Wang, L. (2003). An overview of children's problem behaviors and parenting factors. Journal of Psychological Science, 26(1), 130-132.

Mehroof, M., \& Md., G. (2010). Online gaming addiction: The role of sensation seeking, self-control, neuroticism, aggression, state anxiety, and trait anxiety. Cyberpsychology Behavior \& Social Networking, 13(3).

Podsakoff, P. M., MacKenzie, S. B., Lee, J. Y., \& Podsakoff, N. P. (2003). Common method biases in behavioral research: A critical review of the literature and recommended remedies. Journal of Applied Psychology, 88(5), 879.

Polman, H., de Castro, B. O., \& Van Aken, M. A. G. (2007). Experimental study of the differential effects of playing versus watching violent video games on children's aggressive behavior. Aggressive Behavior, 34(3), 256-264.

Rabkin, J. G., \& Struening, E. L. (1976). Life events, stress, and illness. Science, 194(4269), 1013-1020.

Riley, P., Watt, H. M., Richardson, P. W., \& De Alwis, N. (2012). Relations among beginning teachers' self-reported aggression, unconscious motives, personality, role stress, self-efficacy and burnout. In Interpersonal Relationships in Education (pp. 151-166). Sense Publishers.

Sijtsema, J. J., Oldehinkel, A. J., Veenstra, R., Verhulst, F. C., \& Ormel, J. (2014). Effects of structural and dynamic family characteristics on the development of depressive and aggressive problems during adolescence: The TRAILS study. European Child \& Adolescent Psychiatry, 23(6), 499-513.

Sun, S., Guan, Y., Tan, Y., Zhang, L., \& Fan, F. (2013). Social support and emotional-behavioral problems: Resilience as a mediator and moderator. Chinese Journal of Clinical Psychology, 21(1), 114-118. 
Taylor, S. G., \& Kluemper, D. H. (2012). Linking perceptions of role stress and incivility to workplace aggression: The moderating role of personality. Journal of Occupational Health Psychology, 17(3), 316.

Tedeschi, J. T., \& Felson, R. B. (1994). Violence, aggression, and coercive actions. American Psychological Association.

Wang, E. S. T., \& Wang, M. C. H. (2013). Social support and social interaction ties on Internet addiction: Integrating online and offline contexts. Cyberpsychology, Behavior, and Social Networking, 16(11), 843-849.

Wang, J., \& Li, M. (2012). Moderating and mediating effect of motives on the relation between online games playing and mental health in adolescents. Psychological Exploration, 32(3), 282-286.

Wang, M., \& Zhang, W. (2010). Association between aggressive behavior and Rs6267 functional polymorphism in the COMT gene: The moderating effect of gender and negative life events. Acta Psychologica Sinica, 42(11), 1073-1081.

Wang, X., Wang, X., \& Ma, H. (1999). Rating scales for mental health (Expanded Edition). Bei Jing: Chinese Mental Health Magazine.

Young, K. S. (1998). Internet addiction: The emergence of a new clinical disorder. CyberPsychology \& Behavior, 1(3), $237-244$. 